\title{
O Balanço do ESQUINA: a Trajetória de um Grupo no Âmbito da Extensão Universitária
}

\author{
A Review of ESQUINA: the Trajectory of a Group in the \\ Field of University Extension
}

\section{RESUMO}

Neste trabalho apresentamos e discutimos as ações do Grupo ESQUINA: Cidade, Lazer e Animação Cultural ao longo de seis anos de existência. Atuando no âmbito da Extensão Universitária, tem como bases teóricas os estudos do lazer, como ferramenta pedagógica a animação cultural e o cinema como ponto de partida para suas intervenções.

Palavras-chave: Extensão Universitária. Lazer. Animação Cultural. ESQUINA.

\section{ABSTRACT}

In this work we present and discuss the actions of the group ESQUINA: City, Leisure and Cultural Animation over six years of existence. Acting within the scope of University Extension, the theoretical bases are the studies of leisure, the cultural animation as a pedagogical tool and the cinema as the leading point to its interventions.

Keywords: University Extension. Leisure. Cultural Animation. ESQUINA.

\section{INTRODUÇÃO}

\section{A imagem da universidade pública está fortemente ligada às atividades de} ensino e de pesquisa, e são estas respeitadas dimensões que, aparentemente, consolidam sua importância para a sociedade. Entretanto, sua atuação permaneceria incompleta apoiada apenas sobre estas bases, já que a Extensão também possui papel fundamental na estrutura que compõe as ações da Universidade.

As atividades de extensão configuram o espaço pelo qual a universidade estabelece um diálogo rico e direto com a comunidade. O uso do termo "diálogo" não é aleatório, pois há que se ter cuidado para que esta intervenção não seja confundida

ANGELA BRÊTAS,

ANDréiA LAURITA Vieira

Universidade Federal do Rio de Janeiro. Escola de Educação Física e Desportos, Rio de Janeiro, Brasil 
com atitudes caritativas, elitistas e hierarquizadas nas quais a universidade assume o lugar de detentora de um saber absoluto em detrimento do conjunto de saberes $\mathrm{da}(\mathrm{s})$ comunidade $(\mathrm{s})$.

O relacionamento entre a universidade e a sociedade entabulado pela via da extensão tem que ser pautado pelo respeito e pela consideração de que este encontro é saturado de potência. Tal potência reside na certeza de que há infinitas possibilidades de criação de novos caminhos e de novos conhecimentos em inúmeras áreas de atuação. Contudo, para que esta relação seja efetiva devemos ouvir as vozes de todos e mediar conflitos e interesses sabendo que o imprevisto está cotidianamente no horizonte. Obviamente, esta é uma relação tensa e instável, mas é imprescindível para que a universidade ocupe dignamente seu lugar na sociedade. É a partir dela que temos a chance de abandonar zonas de conforto teórico e colocar em questão o que as teorias nos apresentam. Enfim, a extensão universitária é uma via para formar, reformar e informar, que possibilita o crescimento de todos os envolvidos - docentes, discentes, técnico-administrativos e comunidade. Deste modo, fica clara a assertiva corrente de que a universidade pública se estrutura no tripé formado pelo ensino, pela pesquisa e pela extensão.

Este trabalho tem a intenção de apresentar a trajetória do grupo ESQUINA - Cidade, Lazer e Animação Cultural no que diz respeito às suas intervenções no âmbito da extensão universitária. Sediado na Escola de Educação Física e Desportos da Universidade Federal do Rio de Janeiro (EEFD-UFRJ), foi criado em 2008, e é coordenado pela Profa Dra Angela Brêtas. Ao longo de todo este período, o ESQUINA vem desenvolvendo variados e premiados projetos de extensão tendo o cinema como ponto de partida e a animação cultural como instrumento metodológico. Nestas ações, envolvemos acadêmicos dos cursos de licenciatura e bacharelado em Educação Física e do curso de Letras da UFRJ, que receberam apoio em forma de bolsas do Programa Institucional de Bolsas de Extensão (PIBEX).

Nossa intenção neste artigo é expor as ações que vimos implantando desde 2008 sem detalhes excessivos. Assumindo esta atitude pretendemos criar um espaço para reafirmar a importância da extensão universitária para a formação dos discentes, para a produção de novos conhecimentos e para a sociedade.

\section{O ESQUINA - CIDADE, LAZER E ANIMAÇÃO CULTURAL}

O grupo ESQUINA - Cidade, Lazer e Animação Cultural foi gestado no interior do grupo Anima - Lazer, Animação Cultural e Estudos Culturais, sediado na mesma Universidade e coordenado pelo Prof. Dr. Victor Andrade de Melo durante dez anos. O Anima, hoje extinto, foi responsável pela formação de vários professores e pesquisadores do campo do lazer que seguem atuando na área.

Porém, antes de iniciarmos a apresentação da trajetória do ESQUINA, convém justificar seu nome. Era necessário que o nome do grupo pudesse dar conta de um universo urbano, de encontros, de mistura, de circulação, de espera, de ação, de sabor, de alegria, de ócio e de lazer. Estas demandas estão presentes em esquinas de qualquer 
cidade e, para complementá-las há duas dimensões fundamentais, que são a liberdade e a coletividade. Esquinas são de todos, não podem ser gradeadas e são lugar de vida. Essa é a ambiência que queremos cultivar no interior do grupo.

Nesse sentido, os projetos do ESQUINA buscam absorver tal dinâmica e estabelecer relações entre diferentes saberes. Foram seis intervenções ao longo dos anos de existência do grupo e passaremos a relatá-las de maneira clara e sucinta.

\section{$1^{\circ}$ Projeto}

Como descendentes do Anima, nosso primeiro projeto de extensão deu continuidade a uma pesquisa desenvolvida por esse grupo na Vila Mimosa [8]. Situada na Praça da Bandeira, na cidade do Rio de Janeiro, a Vila Mimosa é uma conhecida área de prostituição. Nas ruas do entorno, há um movimentado comércio de oficinas mecânicas, garagens e pequenas fábricas, assim como bares e botequins frequentados por diferentes tribos urbanas. É grande o número de famílias que residem no local que não gostam, e nem permitem, que sejam identificadas com a prostituição.

Em sua pesquisa, o professor Victor Melo e seus bolsistas observaram que, como qualquer trabalhador autônomo, o tempo/espaço das prostitutas para o lazer era muito restrito. Além disso, não havia diferenças no que tange às tensões que permeiam o lazer de muitas mulheres que trabalham, isto é, dupla jornada de trabalho, fruído no ambiente doméstico e voltado para a família [4].

O primeiro projeto de extensão do ESQUINA foi norteado por estes dados e intitulou-se Cinema, conhecimento e prostituição: uma experiência de animação cultural na Vila Mimosa. Seus objetivos podem ser classificados em duas instâncias. A primeira tem relação com o público que queríamos atingir. A segunda refere-se aos discentes de Educação Física envolvidos na ação. No que tange ao público-alvo do projeto foram quatro objetivos: 1) criar uma condição facilitada de acesso ao lazer, especificamente voltada para a vivência do cinema como fonte de prazer; 2) abrir um espaço de inclusão cultural fortalecendo e ampliando a noção de direito de acesso a bens culturais; 3 ) criar a possiblidade de desenvolvimento do que denominamos "reserva de sensibilidade"; e 4) auxiliar no estabelecimento de condições para o desenvolvimento do que chamamos de uma "autonomia lúdica", isto é, a capacidade autônoma de optar por aquilo que se pretende fruir no lazer.

No que diz respeito aos discentes envolvidos, o projeto deveria se constituir em um espaço de atuação técnica e política, na medida em que teriam contato e poderiam interferir em uma realidade absolutamente diferente daquela que conheciam. Deste modo, havia a possibilidade de crescimento não apenas profissional, mas também e, principalmente, pessoal. Ademais, tornava-se possível e concreta uma formação/ educação cidadã, humanizadora e transformadora.

Cabe ressaltar que esta iniciativa recebeu Menção Honrosa no $5^{\circ}$ Congresso de Ex tensão da UFRJ, realizado em 2008. 
O segundo projeto do ESQUINA foi realizado em parceria com o SESC, unidade Ramos, e intitulou-se Esporte e Cinema dando show. Fomos convidados a desenvolver uma atividade que tivesse relação com o esporte junto a alunos da Escola $\mathrm{Mu}$ nicipal Padre Manoel da Nóbrega, com idade variando entre treze e dezesseis anos, moradores do Complexo do Alemão, conjunto de favelas da zona da Leopoldina na cidade do Rio de Janeiro.

Tivemos toda a liberdade para formatar a intervenção e, movidos pela ideia de ampliar a vivência do esporte em outras dimensões da cultura, o cinema surgiu, mais uma vez, como linguagem interessante e adequada. Também estávamos dispostos a retirar o grupo de adolescentes da condição de espectadores e alçá-los à condição de produtores de cultura. Para vencer este desafio trabalhamos com a experiência de Minuto Lumière [1, apud 2]. Nesta perspectiva os objetivos do projeto foram três: 1) desenvolver competências e habilidades necessárias para uma melhor fruição da linguagem cinematográfica; 2) vivenciar o cinema como fonte de prazer; e 3 ) produzir um filme de um minuto que versasse sobre o esporte. Para cumprir estas metas, lançamos mão dos princípios da educação para e pelo cinema, apresentando aspectos históricos e técnicos da linguagem cinematográfica e filmes de diferentes origens.

Durante um mês, em encontros semanais, iniciávamos as atividades com a apresentação de um curta-metragem ou com uma dinâmica que tivesse relação com uma das quatro grandes temáticas trabalhadas que foram: dança, esportes na natureza, lutas e esportes com bola. As ideias e opiniões que surgiam eram debatidas após a exibição do filme principal. Foram exibidos os longas-metragens: Rizes, de David Lachapelle; Riding Giants,de Stacy Peralta; Rocky, um lutador, de John Avildsen; e Driblando o destino, de Gurinder Chandha.

O projeto foi encerrado com a produção Esporte em minutos*. Conjunto de curtas-metragens com duração de um minuto, produzidos pelos alunos.

\section{$3^{\circ}$ Projeto}

O terceiro projeto intitulou-se ESQUINA no CIEP e foi realizado em parceria com o CIEP César Pernetta, localizado no Parque União, comunidade que compõe o Complexo da Maré.

O público alvo eram jovens e adultos estudantes do ensino fundamental e médio. Os objetivos foram cinco: 1) despertar o interesse pela linguagem do cinema; 2 ) refletir mais amplamente sobre si e sobre a realidade que os rodeia, partindo das discussões acerca das imagens, dos enredos e de outros aspectos que chamassem sua

\footnotetext{
*Esporte em minutos - produções cuja divulgação foi autorizada:

1) Aprendendo a jogar. <http://www.youtube.com/watch?v=oq-uC-bFSLg>

2) Free Willie: a nova geração: <http://www.youtube.com/watch?v=RkXgAmNfJ3s>

Acesso em: 10 de ago. 2013
} 
atenção; 3) construir novos saberes, crenças e valores através do contato com diferentes padrões culturais, normas e costumes; 4 ) vivenciar o cinema como fonte de prazer em outra dimensão da sensibilidade; e 5) desenvolver a já citada "autonomia lúdica”.

Estes objetivos foram materializados em diversas atividades nas quais diferentes linguagens dialogaram e abriram caminhos para que novos conhecimentos fossem construídos. A animação cultural foi a ferramenta metodológica utilizada para estabelecer estes diálogos e, nesta perspectiva, realizamos oficinas nas quais o cinema, a fotografia e a literatura estavam de braços dados e prontos para sair à rua. Assistimos a longas e curtas-metragens, lemos e recriamos poemas, fotografamos espaços da Maré e visitamos centros culturais, interagindo com os locais e com suas exposições. Passeamos pelo centro da cidade do Rio de Janeiro, flanando pelas ruas, descobrindo-as a partir de outros movimentos e de outras lentes, mais cuidadosas, vagarosas, detalhistas, inquietas e curiosas, em um processo de apropriação da cidade que, por direito, é de todos.

Cabe ressaltar que este projeto também recebeu Menção Honrosa no Congresso de Extensão da UFRJ, em 2009.

\section{$4^{\circ}$ Projeto}

O quarto projeto do ESQUINA chamou-se Digestivo Cinematográfico e aconteceu nos corredores da EEFD-UFRJ. Consistia na exibição mensal de curtas-metragens, na hora do almoço, em um espaço de grande circulação de pessoas, próximo à cantina. O local escolhido e a maneira de atuação causavam estranhamento nos espectadores pelo inusitado e pela apropriação subversiva do espaço. O público-alvo era formado por estudantes, técnico-administrativos, docentes, visitantes e passantes. A seleção dos filmes era feita com base em temáticas previamente determinadas pelos integrantes do ESQUINA como, por exemplo, esporte, sexualidade, deficiência e técnicas de animação, dentre outras. Seus objetivos foram dois: 1) possibilitar o contato com a linguagem do cinema, mais especificamente, a dos curtas-metragens; e 2) vivenciar o cinema como mais um elemento sensibilizador do/no processo de ensino e aprendizagem.

Nos dias de projeção, os espectadores cativos chegavam em grupos e os novatos se aproximavam e demonstravam a satisfação de partilhar a produção audiovisual dentro de um espaço improvável para este tipo de mobilização. Improvável porque a Educação Física se estruturou no campo das práticas motoras e por muito tempo negligenciou outras instâncias que também são de grande importância na formação do graduando. Quando pensamos no aflorar das práticas cinematográficas neste ambiente e lançamos mão delas como meio no processo educacional, apontamos novas possibilidades de entendimento e de apreensão do mundo a partir de imagens postas, justapostas, aceleradas e cheias de sentidos e significados.

Percebemos que durante nossa atuação, dois elementos eram de extrema relevância para que as pessoas comparecessem: a temática e o som. Por vezes ouvimos nos corredores "Vou aparecer hoje, hein!? Me amarrei na temática!”. Em outras, ficava claro que o som atraía a atenção dos passantes. O fato é que ainda hoje o Digestivo 
Cinematográfico é lembrado e fica para nós a satisfação de termos "tomado" o espaço que nos é de direito, projetado nossas inquietações nas paredes da EEFD, provocado reações nos espectadores e trocado experiências através de debates que surgiam no momento dos créditos finais e permaneciam até que a vontade de assistir ao filme seguinte fosse motivo de silêncio e de play.

\section{$5^{\circ}$ Projeto}

Em paralelo a todas estas intervenções organizamos os Ciclos de Cinema e Infância. O objetivo geral destes eventos era discutir temáticas relativas à infância tendo o cinema como ponto de partida, ao mesmo tempo em que apresentávamos produções de variadas cinematografias. O público-alvo era formado por discentes, docentes e demais interessados. As exibições aconteciam uma vez por semana, ao longo de um mês. Os filmes selecionados eram exibidos e debatidos por professores convidados. Importa destacar que a seleção dos filmes abria espaços para um emaranhado de questões que não se limitavam à temática norteadora. Deste modo, poderiam também ser discutidas questões de gênero, etnia, classe social e deficiência, dentre tantos outros assuntos.

O primeiro Ciclo foi realizado em 2004, ainda no âmbito do grupo Anima e a seleção dos filmes foi norteada por diferentes temáticas. Deste modo, temas, filmes e debatedores foram, respectivamente: 1) Infância, sociedade e consumo, filme Ladrões de sabonete, direção do italiano Maurizio Nichetti, comentado pela Profa. Dra. Rita Maria Ribes (UERJ); 2) Infância e cidade, filme $O$ espelho dirigido pelo iraniano Jafar Panahi e debatido pela Profa. Dra. Maria Luiza Oswald (PUC-RJ); 3 ) Infância e crítica social, filme Filhos do Paraíso, dirigido pelo iraniano Majid Majidi, analisado pelo Prof. Dr. Walter Kohan (UERJ); 4) Infância e sensibilidade, filme Cinema Paradiso, do italiano Giuseppe Tornatore, comentado pelo Prof. Dr. Luiz Cavalieri Bazílio (UERJ).

O segundo Ciclo aconteceu em parceria com o SESC unidade Engenho de Dentro, no ano de 2007, e teve como temática Infância e Conflitos Armados. A intenção foi discutir o quanto as crianças sofrem com as guerras, na medida em que costumam ser muito atingidas, direta e indiretamente. Os quatro filmes selecionados e respectivos debatedores foram: a) Osama, drama afegão do diretor Siddiq Barmak, debatido pela Profa. Dra. Maria Teresa Goudard (UERJ); b) Império do Sol, dirigido pelo norteamericano Steven Spielberg e discutido pela Profa. Dra. Ruth Cohen (UFRJ); c) Tartarugas podem voar, do diretor iraniano Bahman Ghobadi, analisado pela Profa. Dra. Adriana Fresquet (UFRJ); d) A Infância de Ivan, do diretor russo Andrei Tarkovski, tratado pela Profa. Dra. Lígia Aquino.

O terceiro Ciclo aconteceu em 2010, e a temática norteadora foi Infância e Famílias: as novas conformações familiares. O objetivo foi refletir acerca dos diferentes modos de se viver em família. Os filmes e respectivos professores foram: a) Valentin, do argentino Alejandro Agresti, comentado pela Profa. Dra. Tânia de Vasconcellos (UFF); b) Minha vida de cachorro, dirigido pelo sueco Lasse Hallström, e debatido pela Profa. Dra. Numa Ciro; c) A culpa é do Fidel, dirigido pela cineasta francesa de origem grega Julie Gavras, e debatido pela Profa. Dra. Rosália Duarte (PUC-RJ); d) Um herói 
do nosso tempo, do romeno-israelense Radu Mihaileanu, debatido pelo Prof. Dr. Luiz Felipe Faria (IBMR)**.

O quarto Ciclo foi organizado em 2011 com a temática Infância e Amizade. O interesse foi debater a construção de laços afetivos e de amizade entre crianças. Os filmes e respectivos palestrantes foram: a) Mary e Max, do australiano Adam Elliot e debatido pela Profa. Dra. Maria de Fátima Palmieri (IBMR); b) O menino do pijama listrado, dirigido pelo inglês Mark Herman e analisado pela Profa. Dra. Daniele Corpas (UFRJ); c) O pequeno Nicolau, do francês Laurent Tirard e discutido pelo Prof. Dr. Marcelo Diniz; d) Ponte para Terabítia, do diretor húngaro Gabor Csupo e debatido pela Profa. Dra. Rosane da Silva Gomes (Colégio Pedro II).

\section{$6^{\circ}$ Projeto}

Intitulado Cinema para trabalhadoras da EEFD/UFRJ: a produção de sentidos e de prazer, este projeto recebeu apoio da FAPERJ ${ }^{* * *}$ e teve como objetivo geral exibir filmes que versassem sobre questões referidas ao universo feminino para as mulheres que trabalhavam nos serviços de limpeza da EEFD-UFRJ. Os objetivos específicos foram quatro: 1) garantir um espaço de fruição do cinema; 2) criar oportunidades de ampliação do universo cultural; 3) abrir um lócus de reflexão sobre si mesmas em confronto com outras realidades; e 4) elevar a autoestima e o poder.

Aspectos deste projeto já foram apresentados em dois encontros no ano de 2012, no XIV Congresso Ciências do Desporto e Educação Física dos Países de Língua Portuguesa, e no XIII Seminário O Lazer em debate ${ }^{* * * *}$, portanto, sobre ele não entraremos em maiores detalhes.

\section{PARCERIAS}

Na medida em que as esquinas são lugares de encontros, de trocas e do estabelecimento de parcerias, estamos vivenciando um momento que demonstra o dinamismo do grupo. Estamos recebendo mais uma docente e formalizando uma relação com outro grupo de pesquisa e de extensão. Estes fatos prometem movimentar os próximos anos.

Temos desenvolvido outros projetos no campo da cultura tendo à frente a Profa. Ms. Marcia Moreno, docente da EEFD-UFRJ. Sua chegada ao ESQUINA leva, de certa maneira, à uma retomada das atividades que configuraram o grupo nos seus primeiros anos de atuação.

Além disso, estamos trabalhando em parceria com o Grupo de Estudos e Pesquisa em Educação Física Adaptada e Inclusiva (GEPEFADI), também sediado na EEFD-UFRJ,

\footnotetext{
**Instituto Brasileiro de Medicina de Reabilitação

***Fundação Carlos Chagas Filho de Amparo à Pesquisa do Rio de Janeiro, edital EXTPESO 2010.

$\star \star \star \star \star<h t t p: / / b a z a r 21 . f i l e s . w o r d p r e s s . c o m / 2012 / 05 /$ coletanea-lazer-em-debate-com-capa.pdf>
} 
e coordenado pelas professoras Michelle Pereira, Maitê Russo e Tânia Werner. Nosso primeiro trabalho em conjunto foi a organização do $1^{\circ}$ Ciclo de Cinema e Diversidade, que aconteceu em setembro de 2013, e teve como objetivo geral a discussão das questões relativas à inclusão e à diversidade. Os filmes e respectivos debatedores foram: Saindo do armário, Prof. Dr. Guilherme Freitas; Preciosa, Profa. Dra. Angela Brêtas; Vermelho como o céu, Profa. Ms. Giselle Araújo; Como estrelas na Terra, toda criança é especial, Profa. Dra. Erika Leme.

\section{CONSIDERAÇÕES TEÓRICAS}

São muitas e variadas as fontes da energia que movem o ESQUINA. Como apresentar todas em sua profundidade é tarefa que requer tempo e espaço, talvez, não consigamos fazê-lo de maneira plena neste artigo. Entretanto, é nosso dever, ao menos, apontá-las e discuti-las, ainda que de modo panorâmico.

Em primeiro lugar, somos orientados pelos princípios da extensão, conscientes de que estamos trilhando caminhos nem sempre fáceis e seguros, conforme já foi abordado. Assumimos a posição política de atuar no âmbito do lazer, compreendido como um fenômeno cultural e historicamente situado. Nesta perspectiva, a Animação Cultural é nossa ferramenta de trabalho principal, e o cinema tem sido usado como o elemento detonador, catalisador e agregador das ações, em torno do qual intervimos, buscando estabelecer diálogos com outras linguagens e dimensões culturais. Ademais, nossa intenção é atuar na perspectiva da garantia do direito ao lazer e ao acesso aos bens culturais de pessoas das classes subalternas.

O cinema foi escolhido como ponto de partida para as ações do ESQUINA pela força de sua linguagem e pela possibilidade de adentrar o mundo particular de cada sujeito. Acreditamos que há algo entre a tela e o espectador que não se materializa e, portanto, apresenta-se como etéreo, incorpóreo, intangível e inacessível ao outro. Esta dimensão incontrolável e imponderável diz respeito às vivências, experiências e conhecimentos de cada espectador. Tal dimensão transporta o indivíduo para um universo particular que se clarifica a partir do momento em que ele se coloca e aponta suas impressões acerca daquelas construções imagéticas. A este reporte, isto é, a esta imersão em um contexto criado por imagens, estamos chamando de "contrato lúdico".

O contrato lúdico tem a ver com o encantamento e com a satisfação/insatisfação resultante do contato com um mundo que pode ser fantasioso, mas que preenche necessidades também imateriais de cada indivíduo. Ao acessar um mundo particular, o sujeito não está isolado e nem desconectado do mundo em que se insere. É um universo particular, mas ao mesmo tempo, se relaciona com o universo cultural do qual faz parte. Inferimos que ao acessá-lo, o indivíduo não está desconectado/desligado da realidade. Há a imersão, mas este imergir não foge aos sustentáculos que nos tornam sujeitos de nós mesmos, sujeitos sociais e culturais. Como afirma Plaza "o sujeito da produção e o sujeito da recepção não são pensáveis como sujeitos isolados, mas apenas como social e culturalmente mediados, como sujeitos 'transubjetivos'” [9].

Mas, como não estamos tratando apenas do lugar dos espectadores, a partir do 
instante em que os sujeitos ocupam o lugar da criação, tornam-se produtores e têm a chance de materializar o seu mundo particular. A relevância desta ação está na estruturação, na elaboração, na construção de novos mundos que podem ser compartilhados através de produções visuais ou audiovisuais. Com este entendimento, o ESQUINA, em muitas das atividades explicitadas, utilizou/utiliza oficinas de fotografia e de filmagem na tentativa de alcançar a materialização das "transubjetividades" de cada participante. Destacamos, resumidamente, uma que nos faz sorrir a cada plano, o Cinema Minuto.

O Cinema Minuto consiste em uma intervenção na qual o produto final é um curtíssima de um minuto de duração, com câmera fixa, em plano pré-selecionado. Faz referência aos primeiros filmes rodados pelos irmãos Lumière, pelos idos de 1895, que tinham duração de aproximadamente 52 segundos. Apresenta-se como uma homenagem aos precursores da Sétima Arte e comove por aludir ao primeiro cinema, isto é, às primeiras cenas que influenciariam na grandiosidade que vemos hoje na sala escura. O termo Cinema Minuto foi cunhado pelo grupo ESQUINA, mas o idealizador da oficina foi Alain Bergala, professor francês, que juntamente com a professora Adriana Fresquet, da Faculdade de Educação da UFRJ, disseminaram a experiência entre os graduandos e alunos do Colégio de Aplicação sob o título de Minuto Lumière.

Outra preocupação do ESQUINA é desenvolver a capacidade autônoma de decidir e gerir o que se pretende fruir no tempo de lazer. A este processo intitulamos “autonomia lúdica”. É pelo exercício do cinema que estruturamos as bases para a sua construção, isto é, o cinema é o estopim para uma mobilização de sujeitos independentes para escolha e envolvimento com aquilo que se pretende fruir no lazer. Este é o ponto de partida para o rompimento das barreiras simbólicas que impedem a apropriação da cidade e a vivência do lazer como direito de todos. Com este rompimento, faz-se possível o trânsito por diferentes manifestações, o contato com linguagens antes desconhecidas e inimagináveis e a abertura para outras faculdades do sentir. Cria-se, assim, o que denominamos "uma reserva de sensibilidade", isto é, o vivenciado possibilita ao sujeito guardar e preservar as experiências dos sentidos, podendo - mais à frente - reviver, ressignificar, mostrar ao outro e sentir-se pertencente ao seu tempo e espaço.

Outro conceito que é caro à mediação do grupo é o da circularidade cultural. A ambição de trocarmos conhecimentos com aqueles que se achegam a nós, sermos autônomos ludicamente, reservarmos sensibilidades e auxiliarmos outros nesta construção é possibilitada no momento em que compreendemos que há um "influxo recíproco entre a cultura subalterna e a cultura hegemônica” [3]. Há um intercâmbio, uma circulação, um entrecruzamento que culmina em uma multiplicidade de expressões culturais, as quais alargam os condutos da sensibilidade e apontam que a hierarquização cultural não é o viés a ser seguido quando tratamos da extensão universitária. É importante estarmos atentos às experiências dos outros para que a transposição dos muros da universidade seja próspera e beneficie a todos neste processo de crescimento pessoal tanto dos que estão em contato conosco, como de nós mesmos.

No que tange aos discentes envolvidos, podemos inferir, ainda, que a formação pessoal e a constante inquietação do sujeito, também são pontos relevantes quando 
intentamos formar profissionais comprometidos com a elaboração de estratégias para a construção de sujeitos engajados cultural e politicamente. Antes de querer incutir no outro, não há o que se fazer senão mobilizar a si mesmo. Esfacelar as zonas de conforto e rumar por caminhos estéticos, éticos e multirreferenciais. Imergir-se no processo de circularidade cultural no intuito de acessar uma multiplicidade de expressões que se entrecruzam e culminam na ampliação das nossas vivências. Investir em nossa sensibilidade afim de que a vida, as relações, os desejos ganhem novos contornos.

\section{CONSIDERAÇÕES FINAIS}

O ESQUINA, em seus seis anos de existência, embasado pelos fundamentos do lazer e da animação cultural, procurou atuar neste campo de tensões sempre reafirmando a importância da democratização do acesso ao lazer e às práticas culturais. Os projetos aqui descritos atentam para a urgente compreensão do lazer como um direito e abre possibilidades de fruição do tempo disponível.

Além disso, cremos que a extensão universitária se apresenta como ferramenta essencial para que os discentes tomem ciência da realidade que os cercará ao final dos anos de graduação. É através dela que se pode ter uma visão holística de si e do outro a partir dos embasamentos que a Universidade tanto preza. A oportunidade de praticar a teoria e teorizar a prática é de extrema importância na formação de estudantes, cidadãos humanizados, comprometidos com a mudança.

\section{REFERÊNCIAS}

[1] BERGALA, A. L'hypothèse cinema. Paris: Cahiers du Cinéma, 2002. In: FRESQUET, Adriana (org.). Imagens do desaprender - uma experiência de aprender com o cinema. Rio de Janeiro: Booklink; CINEAD-LISE-FE/ UFRJ, 2007.

[2] FRESQUET, A. (org.) Imagens do desaprender - uma experiência de aprender com o cinema. Rio de Janeiro: Booklink; CINEAD-LISE-FE/UFRJ, 2007.

[3] GINZBURG, C. O queijo e os vermes: o cotidiano e as idéias de um moleiro perseguido pela Inquisição. São Paulo: Cia. das Letras, 1987.

[4] GOELLNER, S. V. et al. Lazer e Gênero nos Programas de Esporte e Lazer das Cidades. Licere, Belo Horizonte, v.13, n.2, jun, 2010.

[5] JANATA, N. E. O trabalho e o lazer/lúdico das meninas-jovens de assentamentos do MST. Motrivivência, Florianópolis v.13, n. 19, jul/dez, 2002. DOI: http://dx.doi.org/10.5007/921

[6] LEIRO, A. C. R. Políticas Públicas e relações de gênero no âmbito do lazer. Revista Brasileira de Ciências do Esporte, v. 21, n. 1, 2001.

[7] MELO, V. A. de. A animação cultural: conceitos e propostas. Campinas: Papirus, 2006. . Lazer e Minorias Sociais. São Paulo: IBRASA, 2003. 
[9] PLAZA, J. Arte e interatividade: autor-obra-recepção. In: ARS (São Paulo). São Paulo. v. 1 n. 2, dez. 2003. Disponível em: <http://www.scielo.br/scielo. php?pid=S1678-53202003000200002\&script=sci_arttext\#back>. Acessado em: 14 de ago de 2013. DOI: http://dx.doi.org/10.1590/S1678-53202003000200002

ANGELA BRÊTAS professora adjunta da Escola de Educação Física e Desportos da Universidade Federal do Rio de Janeiro e coordenadora do ESQUINA - Cidade, Lazer e Animação Cultural - e-mail:labretass@hotmail.com

AndréIA LAURITA VIEIRA licenciada em Educação Física pela Escola de Educação Física e Desportos da Universidade Federal do Rio de Janeiro e integrante do ESQUINA - Cidade, Lazer e Animação Cultural - e-mail: deialaurita@gmail.com 